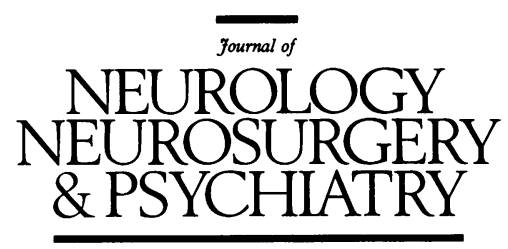

\title{
Editorial
}

\section{Intravenous immunoglobulin treatment in neurological diseases}

Intravenous immunoglobulin (IVIg) was initially introduced as replacement therapy in antibody deficiency disorders. ${ }^{1}$ Later applications include the prophylactic use of IVIg against infections and as an immunomodulating treatment in autoimmune diseases. ${ }^{2-4}$ Overall, the use of intravenous IVIg has increased impressively during the past decade. In 1991, the annual consumption had risen to $428 \mathrm{~kg}^{5}$ in Canada and $200 \mathrm{~kg}$ in the Netherlands, where consumption rose to $250 \mathrm{~kg}$ in 1993.

Doubts exist as to whether this increased use is paralleled by a comparable growth of reliable data on the therapeutic effectiveness of IVIg. To assess the level of evidence on the use of IVIg in neurology, we performed a systematic review of publications in English, using MEDLINE, between January 1981 and January 1995. We looked for comparative trials, case series, and case reports.

There are different levels of evidence on which to base treatment recommendations. The highest are quality data from randomised controlled trials, with double blinding and blinded outcome assessment. The lowest is found in anecdotal, single patient case reports. We found papers reporting on the use of IVIg in 23 neurological disorders (table 1) ${ }^{6-8}$

\section{Guillain-Barré syndrome}

One randomised study compared IVIg with plasma exchange, ${ }^{9}$ with IVIg being slightly superior. $53 \%$ of patients allocated to IVIg improved at least one functional grade on the Guillain-Barré syndrome scale four weeks after onset of treatment against $34 \%$ of the patients allo- cated to plasma exchange. In patients showing signs of deterioration one or two weeks after the initial therapy, a second treatment produced further improvement in most cases. ${ }^{10}$

Of the four open randomised clinical trials that have compared plasma exchange with supportive care, ${ }^{11-14}$ three reported a significant favourable effect. In one of these trials, ${ }^{14}$ the rate of one point improvement on the GuillainBarré syndrome scale four weeks after treatment initiation was $59 \%$ in the plasma exchange group versus $39 \%$ in the control group. In one study, ${ }^{15}$ IVIg in combination with high dose methylprednisolone was compared with historical controls treated with IVIg. The 25 patients with the combination treatment improved earlier than those in the historical control group.

Several ongoing trials are evaluating the effectiveness of IVIg in Guillain-Barré syndrome. These trials are driven by the finding that the success rate in patients allocated to plasma exchange in one trial $^{9}$ comparing IVIg with plasma exchange was similar to the success rate in patients allocated to placebo in the trial ${ }^{14}$ comparing plasma exchange with supportive care.

Published guidelines are not consistent in their treatment recommendations. The University Hospital Consortium (UHC) Expert Panel ${ }^{16}$ seem to have accepted the results of the Dutch Guillain-Barré syndrome trial as they formulated in a consensus statement that IVIg may be considered as an equivalent alternative to plasma exchange. According to the guidelines of the Australasian Society of Blood Transfusion (ASBT) ${ }^{17}$ plasma exchange is still preferred to IVIg.

Review of published articles on IVIg treatment in MEDLINE between fanuary 1981 until fanuary 1995

\begin{tabular}{|c|c|c|c|c|}
\hline Neurological disorder & $\begin{array}{l}\text { Randomised } \\
\text { trials }\end{array}$ & $\begin{array}{l}\text { Uncontrolled } \\
\text { series* }\end{array}$ & $\begin{array}{l}\text { Total No of } \\
\text { patients in series }\end{array}$ & $\begin{array}{l}\text { No of patients } \\
\text { responding (\%) }\end{array}$ \\
\hline Guillain-Barré syndrome & 1: COM & 11 & 75 & $55(73)$ \\
\hline $\begin{array}{l}\text { Chronic inflammatory demyelinating } \\
\text { polyneuropathy }\end{array}$ & 1: PC,1: CR & 7 & 103 & $66(64)$ \\
\hline Multifocal motor neuropathy & 1: CR & 4 & 21 & $17(81)$ \\
\hline Myasthenia gravis & & 9 & 119 & $84(71)$ \\
\hline Dermatomyositis & 1: PC & 5 & 25 & $20(80)$ \\
\hline Polymyositis & - & 3 & 21 & $13(62)$ \\
\hline Inclusion body myositis & - & 2 & 15 & $3(20)$ \\
\hline Refractory epilepsy of childhood & - & 14 & 189 & $98(52)$ \\
\hline Multiple sclerosis & 1: OP & 3 & 31 & \\
\hline -optic neuritis & - & 1 & 5 & $4(80)$ \\
\hline Paraproteinaemic polyneuropathy & - & 1 & 2 & $2(100)$ \\
\hline Amyotrophic lateral sclerosis & - & 1 & $\overline{9}$ & 0 \\
\hline HTLV associated myelopathy & - & 1 & 14 & $10(71)$ \\
\hline Lumbosacral plexopathy & - & 1 & 2 & $2(100)$ \\
\hline Stiff-man syndrome & - & 2 & $\overline{6}$ & $6(100)$ \\
\hline Rasmussen's syndrome & - & 1 & 9 & $7(78)$ \\
\hline Adrenoleukodystrophy & - & $t$ & & \\
\hline Lambert-Eaton syndrome & - & $\dot{t}$ & & \\
\hline Miller Fisher syndrome & - & $t$ & & \\
\hline Opsoclonus polymyoclonia syndrome & - & $\dot{t}$ & & \\
\hline Isaacs' syndrome & - & $t$ & & \\
\hline Paraneoplastic cerebellar syndrome & - & $\dot{t}$ & & \\
\hline Echovirus meningoencephalitis & - & $\dot{t}$ & & \\
\hline
\end{tabular}

^Series in which at least two patients were described.

tFor these disorders only single case reports have been published.

$\mathrm{COM}=$ comparative trial; $\mathrm{PC}=$ placebo-controlled trial; $\mathrm{CR}=$ cross over trial; $\mathrm{OP}=$ open trial 
Chronic inflammatory demyelinating polyneuropathy

A placebo controlled cross over study ${ }^{18}$ was performed, in which IVIg was given to a selected group of patients with chronic inflammatory demyelinating polyneuropathy who had all shown a favourable response to IVIg in previous open studies. The disability of all patients improved after IVIg and did not change or deteriorate after placebo. These beneficial effects of IVIg could not be confirmed in a double blind randomised trial ${ }^{19}$ in newly diagnosed patients with the disease. Recently, one randomised study (which appeared in MEDLINE after January 1995) compared IVIg with plasma exchange in which no differences were found between the groups in the short term. In a recently completed study from Canada, patients on IVIg had better results than those on placebo. The details of this study have not yet been published.

Alternative therapies are corticosteroids and plasma exchange. For both treatments statistically significant differences in favour of treatment were shown in simple randomised controlled trials. ${ }^{21}{ }^{22}$ These trials had an outcome measure that was a mixture of impairment and disability scores. ${ }^{23}$

There is still no consensus on the use of IVIg in chronic inflammatory demyelinating polyneuropathy. In 1993, the ASBT $^{17}$ recommended IVIg as first line treatment for children who were too small for plasma exchange, but after that publication more information became available. In 1995, the UHC Expert Panel ${ }^{16}$ considered IVIg an equivalent alternative to plasma exchange. They did not discuss the role of steroids, which by many are considered as treatment of first choice.

\section{Multifocal motor neuropathy}

In a placebo controlled cross over study, ${ }^{24}$ in which 12 patients with motor neuron syndromes associated with high titres of anti-GM $\mathrm{G}_{1}$ antibodies were treated, IVIg induced significant increases in muscle strength only in patients with conduction blocks. In uncontrolled series IVIg was usually given at one to two month intervals. Alternative therapies are corticosteroids ${ }^{25}$ and cyclophosphamide. ${ }^{26}$ Some patients deteriorated after treatment with corticosteroids. Beneficial effects of cyclophosphamide have been described in small uncontrolled series.

In multifocal motor neuropathy IVIg is the only treatment that has been tested in a controlled study but it is unlikely that this treatment is universally accepted as first line treatment. A recent report ${ }^{27}$ concluded that patients with multifocal motor neuropathy may temporarily improve after IVIg but that the disease progresses and that patients continue to deteriorate. The UHC Expert Panel ${ }^{16}$ did not recommend the use of IVIg in motor neuron syndromes.

\section{Myasthenia gravis}

For this disease the use of IVIg has only been studied in anecdotal case series except for one randomised controlled trial which has just been completed. ${ }^{28}$ Preliminary analysis does not show any difference from plasma exchange (Ph Gajdos, personal communication). In most studies patients were treated during an acute crisis, in others during a more stable chronic phase of the disease, or the stage of the disease was not described. Comparison of treatment responses in case series was difficult, as many different primary outcome measures were used. Usually, IVIg treatment was given once and was not repeated. Some patients who had failed to respond to plasma exchange responded to IVIg and vice versa. ${ }^{29}$ Alternative therapies include immunosuppression and plasma exchange. Plasma exchange has not been tested in randomised trials. In large studies ${ }^{30}$ the response rate was estimated at $70 \%$, which is comparable with the estimated response rate reported after IVIg. In both the UHC Expert panel and the ASBT guidelines, plasma exchange is preferred to IVIg.

\section{Inflammatory myopathies}

The inflammatory myopathies include dermatomyositis, polymyositis, and inclusion body myositis. In dermatomyositis, IVIg was shown to be effective in a placebo controlled trial ${ }^{31}$ in patients who had become resistant to immunosuppressive drugs. IVIg was given in two doses of $1 \mathrm{~g} / \mathrm{kg}$ on two consecutive days, instead of the usual schedule of $0.4 \mathrm{~g} / \mathrm{kg}$ for five days. Patients continued to receive prednisone during the trial. The main outcome measure was improvement in muscle strength. In case series IVIg usually was given at monthly intervals to patients in whom steroids were unsuccessful or contraindicated and outcome measures were based on measurement of muscle strength.

Effectiveness of IVIg in polymyositis was studied in three uncontrolled series with various results. ${ }^{32-34}$ In one study $^{35}$ beneficial effects of IVIg were described in four patients with inclusion body myositis, a disorder which is considered to be resistant to all therapies. However, in another study ${ }^{36}$ in nine patients, none improved after IVIg.

Corticosteroids are usually considered as first line therapy in inflammatory myopathies. ${ }^{37}$ If not effective, other immunosuppressive treatment is used, but again there are no controlled studies. In a placebo controlled trial there was no beneficial effect of plasma exchange ${ }^{38}$ in patients with dermatomyositis or polymyositis.

Since IVIg was tested in a clinical trial in patients resistant to other therapies, IVIg treatment cannot be recommended as first line therapy as is shown in published guidelines: Dalakas et $a l^{39}$ recommend IVIg in inflammatory myopathies after failure of steroids and/or azathioprine. The UHC Expert Panel recommend IVIg for both dermatomyositis and polymyositis in patients with severe active illness for whom other interventions have been unsuccessful or intolerable. For inclusion body myositis, evidence from the medical literature does not support the use of IVIg.

\section{Refractory epilepsy of childhood}

Treatment with IVIg was studied in a very heterogenous group of children with refractory epilepsy..$^{40}$ All studies were uncontrolled, except one single blind placebo controlled add on trial, ${ }^{41}$ in which the children were their own controls. These children had different forms of epilepsy, both focal and generalised. Of all children studied, about $30 \%$ had Lennox-Gastaut syndrome and $25 \%$ had West syndrome. Anticonvulsive drugs had been unsuccessful in most children, including ACTH in some. Usually, IVIg was given at intervals of two or three weeks and the reduction in the number of seizures was used as the outcome measure, but in many studies an accurate definition of outcome measures was lacking. In a few studies an association was found between deficiencies of IgG subclasses before treatment and a favourable response to IVIg. Recently, a double blind dose/finding clinical trial ${ }^{42}$ (appeared in MEDLINE after January 1995) showed a positive trend in favour of IVIg, but the difference was not significant in comparison with placebo.

New antiepileptic drugs such as vigabatrin may be considered as alternatives to IVIg. Direct comparison has not been carried out. In adults, clinical trials have shown 
effectiveness of vigabatrin ${ }^{43}$; in children a beneficial effect was suggested in uncontrolled trials with a response rate of $40-70 \%{ }^{44}$

In the UHC Expert Panel guidelines, there is only a place for IVIg as a last resort, especially in patients who are candidates for surgical resection.

In conclusion, for most of the disorders listed in the table, only case series have been published. Therefore, the data on therapeutic effectiveness to support the use of IVIg are not very strong. The disorders for which there is better evidence than case series to use IVIg treatment, are relatively rare. The large consumption of IVIg, as has been shown for different countries such as Canada and The Netherlands, can therefore probably not be explained by an increased use of IVIg in neurological patients.

A OTTEN $M$ VERMEULEN

\section{Department of Neurology}

Department of Clinical Epidemiology and Biostatistics P M M BOSSUYT

Academisch Medisch Centrum,

University of Amsterdam,

Amsterdam, The Netherlands

Department of Neurology,

Leyenburg Hospital,

The Hague, The Netherlands

Correspondence to: Professor M Vermeulen, Department of Neurology, H2-214, Academisch Medisch Centrum, Meibergdreef 9, 1105 AZ Amsterdam, The Netherlands.

1 Schwartz SA. Clinical use of immune serum globulin as replacement therapy in patients with primary immunodeficiency syndromes. Clin Rev Allergy 1992;10:1-12.

2 Fanaroff AA, Korones SB, Wright LL, Wright EC, Poland RL, Bauer CB, et al. A controlled trial of intravenous immune globulin to reduce nosocomial infections in very-low-birth-weight infants. National Institute of Child Health and Human Development Neonatal Research Network. $N$ Engl f Med 1994;330:1107-13.

3 Sullivan KM, Kopecky KJ, Jocom J, Fischer L, Buckner CD, Meyers JD, et al. Immunomodulatory and antimicrobial efficacy of intravenous immunoglobulin in bone marrow transplantation. $N$ Engl $f$ Med immunoglobulin

4 Ronda N, Hurez V, Kazatchkine MD. Intravenous immunoglobulin therapy of autoimmune and systemic inflammatory diseases. Vox Sang 1993;64:65-72.

5 Rock GA. Intravenous immunoglobulins [editorial]. Transfusion Science 1992;13:265.

6 Soueidan SA, Dalakas MC. Treatment of autoimmune neuromuscular diseases with high-dose intravenous immune globulin. Pediatr Res 1993;33(suppl):S95-S100.

7 Levinson AI. The use of IVIg in neurological disease. Clin Rev Allergy 1992;10:119-34.

8 Thornton CA, Griggs RC. Plasma exchange and intravenous immunoglobulin treatment of neuromuscular disease. Ann Neurol 1994;35:260-8.

9 van der Meché FGA, Schmitz PIM and the Dutch Guillain-Barré Study Group. A randomized trial comparing intravenous immune globulin and plasma exchange in Guillain-Barré syndrome. $N$ Engl $f$ Med 1992; 326:1123-9.

10 Kleyweg RP, Van Der Meché FGA. Treatment related fluctuations in Guillain-Barré syndrome after high-dose immunoglobulins or plasma exchange. F Neurol Neurosurg Psychiatry 1991;54:957-60.

11 Greenwood RJ, Newsom-Davids J, Hughes RAC, Aslan S, Bowden AN, Chadwick DW. Controlled trial of plasma exchange in acute inflammatory polyradiculoneuropathy. Lancet 1984;i:877-9.

12 Osterman PO, Fagius J, Lundemo G, Pihlstedt P, Pirskanen R, Siden A, et al. Beneficial effects of plasma exchange in acute inflammatory polyradiculoneuropathy. Lancet 1984;2:1296-8.

13 French Cooperative Group on Plasma Exchange in Guillain-Barré Syndrome. Efficiency of plasma exchange in Guillain-Barré syndrome: role of replacement fluids. Ann Neurol 1987;22:753-61.

14 The Guillain-Barré syndrome study group. Plasmapheresis and acute Guillain-Barré syndrome. Neurology 1985;35:1096-104.

15 The Dutch Guillain-Barré Study Group. Treatment of Guillain-Barré syndrome with high-dose immune globulins combined with methylprednisolone: a pilot study. Ann Neurol 1994;35:749-52.

16 Ratko TA, Burnett DA, Foulke GE, Matuszewski KA, Sacher RA and the University Hospital Consortium Expert Panel. Recommendations for off- label use of intravenously administered immunoglobulin preparations. Consensus statement. FAMA 1995;273:1865-70.

17 Keller T, McGrath K, Newland A, Gatenby P, Cobcroft R, Gibson J for the Australasian Society of Blood Transfusion: indications for use of intravenous immunoglobulin. Recommendations of the Australasian Society of Blood Transfusion. Med f Aust 1993;159:204-6.

18 van Doorn PA, Brand A, Strengers PFW, Meulstee J, Vermeulen M. Highdose intravenous immunoglobulin treatment in chronic inflammatory demyelinating polyneuropathy: a double-blind, placebo-controlled, crossover study. Neurology 1990;40:209-12.

19 Vermeulen M, van Doorn PA, Brand A, Strengers PFW, Jennekens FGI, Busch HFM. Intravenous immunoglobulin treatment in patients with chronic inflammatory demyelinating polyneuropathy: a double blind placebo controlled study. I Neurol Neurosurg Psychiatry 1993;56:36-9.

20 Dyck PJ, Litchy WJ, Kratz KM, Suarez A, Low PA, Pineda AA, et al. A plasma exchange versus immune globulin infusion trial in chronic inflammatory demyelinating polyradiculoneuropathy. Ann Neurol 1994;36: 838-4520.

21 Dyck PJ, O'Brien PC, Oviatt KF, Dinapoli RP, Daube JR, Bartleson JD, et al. Prednisone improves chronic inflammatory demyelinating polyradiculoneuropathy more than no treatment. Ann Neurol 1982;11:136-41.

22 Dyck PJ, Daube J, O'Brien P, Pineda A, Low PA, Windebank AJ, et al. Plasma exchange in chronic inflammatory demyelinating polyradiculoneuropathy. N Engl f Med 1986;314:461-5.

23 Molenaar DSM, de Haan $R$ Vermeulen $M$ Impairment, disability or handicap in peripheral neuropathy: analysis of the use of outcome measures in clinical trials in patients with peripheral neuropathy. $\mathcal{f}$ Neurol Neurosurg Psychiatry 1995;59:165-9.

24 Azulay JP, Blin O, Pouget J, Boucraut J, Billé-Turc F, Carles G, et al. Intravenous immunoglobulin treatment in patients with motor neuron syndromes associated with anti-GM $\mathrm{G}_{1}$ antibodies: a double-blind, placebo-controlled study. Neurology 1994;44:429-32.

25 Pestronk A, Chaudry V, Feldman EL, Griffin JW, Cornblath DR, Denys $\mathrm{EH}$, et al. Lower motor neuron syndromes defined by patterns of weakness, nerve condition abnormalities, and high titers of antiglycolipid antibodies. Ann Neurol 1990;27:316-26.

26 Feldman EL, Bromberg MB, Albers JW, Pestronk A. Immunosuppressive treatment in multifocal motor neuropathy. Ann Neurol 1991;30:397-401.

27 Elliott JL, Pestronk A. Progression of multifocal motor neuropathy during apparently successful treatment with human immunoglobulin. Neurology $1994 ; 44: 967-8$.

28 Gajdos $\mathrm{Ph}$. Intravenous immune globulin in myasthenia gravis. Clin Exp Immunol 1994;97(suppl 1):49-51.

29 Stricker RB, Kwiatkowska BJ, Habis JA, Kiprov DD. Response to plasmapheresis following failure of intravenous gammaglobulin. Arch Neuro 1993;50:837-40

30 Cornelio F, Antozzi C, Mantegazza R, Confalonieri P, Berta E, Peluchetti D et al. Immunosuppressive treatments: their efficacy on myasthenia gravis patients' outcome and on the natural course of the disease. Ann NY Acad Sci 1993;681:594-602.

31 Dalakas MC, Illa I, Dambrosia JM, Soueidan SA, Stein DP, Otero C, et al. A controlled trial of high-dose intravenous immune globulin infusions as terment for dermatomyositis. N Engl F Med 1993;329:1993-2000.

32 Cherin P, Herson S, Wechsler B, Piette JC, Bletry O, Coutellier A, et al. Efficacy of intravenous gammaglobulin therapy in chronic refractory polymyositis and dermatomyositis: an open study with 20 adult patients. Am F Med 1991;91:162-8.

33 Jann S, Beretta S, Moggio M, Adobbati L, Pellegrini G. High-dose intravenous human immunoglobulin in polymyositis resistant to treatment. $\mathcal{f}$ Neurol Neurosurg Psychiatry 1992;55:60-2.

34 Cherin P, Piette JC, Wechsler B, Bletry O, Ziza JM, Laraki R, et al. Intravenous gamma globulin as first line therapy in polymyositis and dermatomyositis: an open study in 11 adult patients. $f$ Rheumato 1994;21:1092-7.

35 Soueidan SA, Dalakas MC. Treatment of inclusion-body myositis with high-dose intravenous immunoglobulin. Neurology 1993;43:876-9.

36 Amato AA, Barohn RJ, Jackson CE, Pappert EJ, Sahenk Z, Kissel JT. Inclusion body myositis: treatment with intravenous immunoglobulin. Neurology 1994;44:1516-8.

37 Dalakas MC. Polymyositis, dermatomyositis, and inclusion-body myositis [review]. N Engl ₹ Med 1991;325:1487-98.

38 Miller FW, Leitman SF, Cronin ME, Hicks JE, Leff RL, Wesley R, et al Controlled trial of plasma exchange and leukapheresis in polymyositis and dermatomyositis. N Engl f Med 1992;326:1380-4.

39 Dalakas MC. Clinical, immunopathologic, and therapeutic considerations of inflammatory myopathies. Clin Neuropharmacol 1992;15:327-51.

40 Gross-Tsur V, Shalev RS, Kazir E, Engelhard D, Amir N. Intravenous high-dose gammaglobulins for intractable childhood epilepsy. Acta Neurol Scand 1993;88:204-9.

41 Illum N, Taudorf $\mathrm{K}$, Heilmann $\mathrm{C}$, Smith $\mathrm{T}$, Wulff $\mathrm{K}$, Mansa B, et al. Intravenous immunoglobulin: a single-blind trial in children with Lennox-Gastaut syndrome. Neuropediatrics 1990;21:87-90.

42 van Rijckevorsel-Harmant K, Delire M, Schmitz-Moorman W, Wieser HG. Treatment of refractory epilepsy with intravenous immunoglobulins. Results of the first double-blind/dose finding clinical study. Int $₹$ Clin Lab Res 1994;24:162-6.

43 Conelly JF. Vigabatrin. Ann Pharmacother 1993;27:197-204.

44 Appleton RE. The role of vigabitrin in the management of infantile epileptic syndromes. Neurology 1993;43(suppl 5):S21-3. 